\title{
Simulation as a Recruitment Strategy: A Pilot Study
}

\author{
Barbara Ann M. Messina, PhD, RN, ANP \\ Assistant Professor \\ Director of Clinical Nursing Simulation Education \\ Molloy College \\ Brian Haughney, AAS, EMT-P, CIC \\ Simulation Lab Coordinator \\ Nursing Professional Development \\ Memorial Sloan Kettering Cancer Center
}

\begin{abstract}
Attrition rates of baccalaureate degree science, technology, engineering and mathematic programs (STEM) is between 45\% - 50\% (U.S. Education Department, 2013). Attrition prolongs career goal attainment and is costly to students and families.In addition to providing a high quality education Long Island University/Post (LIU/Post) is committed to assisting students to match their career goals to their selected program majors. In order for students to select program majors that matches their career goals, students need to gain insight into the professional role of their selected program major.Utilizing the theoretical constructs of situated learning (Lave \& Wenger, 1991) an interprofessonal simulated immersion experience was created and presented in the LIU/Post Interprofessional Simulation Center (IPC) during a 2017 summer immersion experience. The purpose of this program was to assist high school students interested in entering healthcare to gain insight into the professional roles of various members of the health care team.
\end{abstract}

\section{Recruitment}

The demand for health care occupations is expected to continue to grow. Moreover, as the U.S. population continues to age the demand for health care occupations is not only expected to continue to grow but to exceed the demand for all other occupations in the U.S (U.S. Department Census Bureau, 2017; U.S. Department of Labor, 2017).

\section{Attrition of Undergraduate Baccalaureate Degree Students Enrolled in STEM Programs}

In 2013 the U.S. Education Department's National Center for Education and Statistics published the results of a longitudinal study that was conducted over a six year period. The study tracked attrition rates of students enrolled in Associate and Baccalaureate degree programs from 2003 - 2009. The study found $48 \%$ of students enrolled in a Baccalaureate degree program and 69\% of students enrolled in an Associate degree program left the STEM fields by spring 2009.

LIU/Postis committed to not only providing a high quality education to meet the nations demand for well-educated health care providers but also to assisting students to gain insight into the role, function and scope of practice of the occupations of the various members of interprofessionalhealth care team prior to students selecting their program majors.

\section{LIU/Post IPC: Gaining Insight to the Role}

The purpose of the LIU/Post Summer Honors Institute (SHI) is to provide high school (HS) students with a preview of college life as well as providing HS students who are interested in pursuing a career in healthcare the ability to gain insight into the role, function and scope of practice of the various occupations of the interprofessional health care team. Utilizing the theoretical constructs of situated learning (Lave \& Wenger, 1991) an interprofessional (IPE) simulation immersion experience was created and presented in the LIU/PostIPC.Situated learning necessitates the learner to participate in the social processes of the circumstance. Thereby, providing the learner with the opportunity to not only know the didactic content but also to learn and experience the activities of specific people in specific circumstances (Lave \& Wenger, 1991).

\section{SHI Immersion Experience: Introduction and Preparation}

LIU/Post offers multiple four year Baccalaureate and Master's degree programs in various health care professions. Sixty HS students; male and female from Arizona, California, Florida, Georgia, New Jersey, New York, Pennsylvania, South Carolina and Virginia participated. 
All of the HS students expressed an interest in pursuing a career in the one of the seven represented health science professions that participated in the week long immersion experience at LIU/Post, July 2017.

Faculty representatives of the; four year pre-licensure nursing program, family nurse practitioner(FNP), radiology technician, registered dietician, social work, biomedical sciences (clinical laboratory) and the pharmacology D. professional programs, actively participated and acted as mentors, facilitators and guides during the week long simulated immersion experience.The activity planning for the week long immersion experience, the simulated immersion experience at the LIU/Post IPC and the ice breakers were designed and facilitated by the faculty who participated.

Prior to the ice breakers and the immersion experience a careers profile seminar was presented. All of the HS students attended. The purpose of the careers profile seminar was to provide a general overview of the role, function, scope of practice and discussion of the specific activities that are associated with each of the seven respresentedhealth care professions. Faculty representatives of the seven representedhealth care professions discussed their specific discipline during the careers seminar.

Upon conclusion of the careers profile seminar and after lunch all of the HS students partook in an American Heart Association Basic Cardiac Life Support (BCLS) training course. All participants became BCLS certified in preparation for the simulated immersion experience. The $60 \mathrm{HS}$ students were then divided into ten groups. Each group was assigned a faculty representative who remained with the group throughout the week. The immersion experience began with a series of ice breakers. The ice breaker activities were designed to facilitate socialization amongst the HS students, foster team building skills and permit the HS students and faculty to become acquainted. The ice breakers were inter-dispersed throughout the week.

\section{Interdisciplinary Role Assignment}

The simulated clinical immersion experience began the second day. The simulated immersion experience was designed to engage the HS students in the activities that are specific to each of the represented disciplines of the interprofessional health care team. Each groupwas rotated through the simulated immersion experience throughput the week.Prior to the initiation of each of the simulated clinical immersion experiences the HS students were assigned to a specific role of the interdisciplinary health care team. The HS students were then partnered with the faculty who were experts in that specific role. Expert faculty lead the HS students through the simulated immersion experience(s) assisting and guiding them through the specific tasks, functions and activities that are specific to the specific role to which they were assigned. As the simulated immersion experience evolved throughout the week the HS students were rotated and assigned to each of the seven specific roles that were represented. Thereby, permitting the student(s) to experience each individual role as well as working within that role as a member of the interprofessional health care team.

Furthermore, it is also to be noted that the HS students were purposefully assigned to the same role multiple times throughout the week. This was done so the HS student could immerse themselves in variety of clinical experiences and circumstances of the role. By providing participants with a variety of simulated clinical circumstances that are specific to a role this provided the HS students to experience multiple facets and activates that is associated with each the specific role(s) to which they were assigned. Thus, permitting them to gain greater insight into the depth and breadth associated with the various roles of the interprofessional health care team (Lave \& Wenger, 1991).

\section{The Simulated Immersion Experience Clinical Simulation}

The clinical immersion experience began by staging a car accident. A wrecked car was placed against a tree on the LIU/Post campus. The local police department generously gave of their time and participated in the clinical scenario throughout the week. The scenario begins when the local police highway patrol finds the motor vehicle accident. The police officer examines the wreck, finds a victim trapped in the car, calls an ambulance (LIU/Post emergency ambulance) and begins to administer first aide to the victim trapped in the wrecked car. Upon arrival of the LIU/Post ambulance the LIU/Post emergency medical technicians extract the victim from the car wreck. The victim is placed in the LIU/Post ambulance and the victim is then transported to the nearest level 1 trauma center, the LIU/Post IPC. The LIU/Post IPC is equipped with state of the art emergency equipment including high fidelity $3 \mathrm{G}$ sim man ${ }^{\circledR}$ manikins. The radiology technician program which is located one floor down from the LIU/Post IPC hosts a fully functioning radiology laboratory. As each emergent medical condition presents an x-ray is necessitated as part of the diagnostic medical evaluation work-up.

The LIU/Post biomedical sciences (clinical laboratory) also hosts a fully functioning laboratory.As laboratory specimens were obtained and brought to the biomedical sciences (clinical laboratory). The students than conducted and ran the assigned diagnostic study that was ordered. 
Upon conclusion of the diagnostic study the students were than required to call and report the findings to the FNP's.Pharmacology D., social work and the registered dietician.Roles and participation within the immersion experience was also high interactive.Members of LIU/Post administrative hierarchy participated as confederates within the immersion experience as family members of the accident victim.

\section{Study Participant Demographics and Consent}

All of the HS students were entering their senior yearand wererecruited locally, regionally and nationally. All accepted students received free tuition and housingfor the week long expereince. Participantages ranged from $16-17$ years of age. After approval by the LIU/Post Institutional Review Board (IRB) was obtained a study consent was mailed to the parents/guardians of all of the accepted students prior to the student's arrival. All accepted students agreed to participate in the study.

\section{Study Tool}

The Student Stereo Typing Rating Questionnaire [SSTRQ] (Hean, Macleod, Adams \&Humphris, 2006) was utilized. Permission to use the tool was sought and obtained. The SSTRQ (Hean et al., 2006) is a five point Likert scale that asks the participants to rate specific health care professions on the following variables:Student Stereo Typing Rating Questionnaire [SSTRQ] (Hean et al., 2006)

\begin{tabular}{|c|c|c|c|c|c|}
\hline & VeryHigh & & & & VeryLow \\
\hline How would you rate $\mathbf{X X X}$ on: & 5 & 4 & 3 & 2 & 1 \\
\hline Academic ability & & & & & \\
\hline Professional competence & & & & & \\
\hline Interpersonal skills (e.g., warmth, sympathy, communication) & & & & & \\
\hline Leadership abilities & & & & & \\
\hline The ability to work independently & & & & & \\
\hline The ability to be a team player & & & & & \\
\hline The ability to make decisions & & & & & \\
\hline Practical skills & & & & & \\
\hline Confidence & & & & & \\
\hline
\end{tabular}

\section{SSTQR: Content Validity}

The SSRQ content validity was established by a panel of academics, health and social care professionals. Test and retest reliability of each item on the questionnaire was tested, and items not reliable over time at a 5\% significance level were not used.

\section{Study Design}

Participants were asked to complete the SSTRQ (Hean et al., 2006) upon arrival during registration. Registration of the HS students was done by Administrative Assistant Personnel. Therefore, the SSTRQ (Hean et al., 2006) was completed prior to the HS students interacting with faculty and/or prior to engaging in the ice breakers or simulated immersion experience(s).

At the conclusion of the week long experience the HS students were again asked to complete the SSTRQ (Hean et al., 2006). In addition the HS students were also asked to complete a program evaluation. The program evaluation provided HS students with the opportunity to provide comments regarding their experience(s).

\section{Quantitative Study Data}

Each of the seven group scores were separated out. The average score of each group was calculated for the before and after score for each of the seven groups. Seven paired T tests were conducted, one for each of the seven groups. The total before and after average scores were calculated and a paired sample $\mathrm{T}$ test was conducted for the total scores.Student participant demographics; state and gender were also examined. A LIU/Post State or Not Variable was created. A linear regression was conducted to examine if the variables could predict the after scores (dependent variable); before scores, gender and LIU/Post State or not independent variables.

\section{Quantitative Data Study Results}

Statistical significance changes were found in all sub scores and in the total scores. State and gender did not add to the explanation of the after scores. 


\section{Average after Scores per Group Graph would be placed here.}

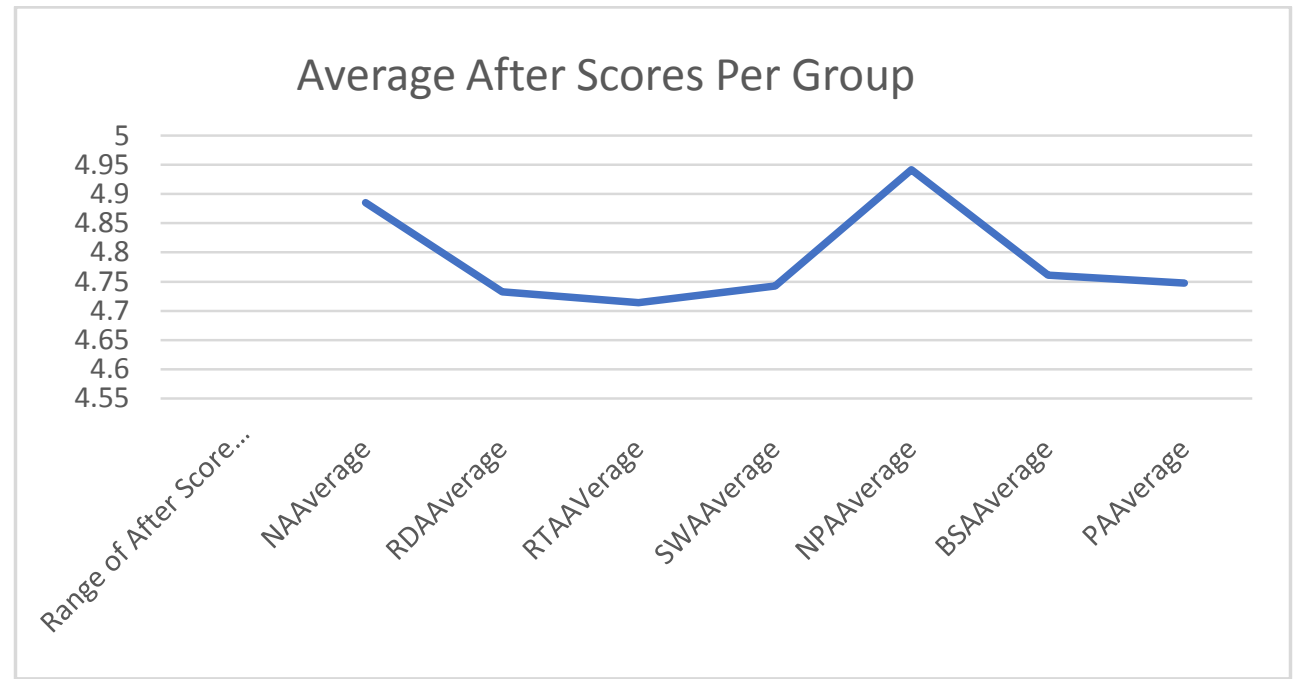

Abbreviations:

- N: Nurse (baccalaureate)

- RD: Registered Dietician

- RT: Radiology Technician

- SW: Social Work

- NP: Nurse Practitioner

- BS: Biomedical Sciences (Clinical Laboratory Sciences)

- P: Pharmacist

\section{Qualitative Data}

Qualitative data obtained on the overall immersion experience was reviewed. Two reoccurring themes emerged. The first theme to emerge was how the opportunity to observe and interact with various members of the health care team provided insight into the roles of the interprofessional health care team. The second theme to emerge was how the students felt comfortable and supported in the experience and interactions with the faculty.

What did you like best about the program?

"Real life people speaking about their careers."

".......... learning about the various careers of healthcare."

"Learning different areas within the medical field and being exposed to the actual equipment."

"It gave me an opportunity to learn more about the career I want to pursue and also learn that in the healthcare industry, you must learn to work as a team not as an individual."

"It gave me good insight into many different healthcare careers and let me participate hands on in related activities. It was a great experience. I love the CPR."

Would you recommend this program to your friends and school guidance counselors, and why?

"Yes, I would because it was an insightful program that helps people find their passion."

Yes, it helped me to realize that I do actually want to work in the medical field as an oncology nurse practitioner."

"Yes, I definitely will because it allows you to discover more options in the medical field and is a great experience."

"Yes, I would recommend the program because it allowed me to learn more about health care in general and discover careers I didn't know about. It really opened up my horizon. I think the program is perfect for people who are unsure what career they want to pursue in health care."

"Yes, I would recommend the program because it taught a lot. It was informative, interactive and fun. It would be a great opportunity for other students to attend so they can learn about different careers in medicine and get to experience all aspects of the medical field."

Additional Comments

"Yes, super fun and I learned a lot."

"Yes, this program is fun and educational at the same time."

"Yes, you get a good college experience and learn new things."

"Yes, great experience and learned information."

"There were so many people were involved and willing to help. They were also nice people to spend a week with." 


\section{Conclusion}

Learning environments where students feel supported and the students enjoy the teaching space assist students to develop insight and confidence (McDowell, Styles, Sewell, Trinder, Marriott, Maher \& Naidu, 2016; Vardi, 2016). The quantitative and qualitative results indicate the students and felt comfortable, enjoyed the learning experience(s) and gained insight into the various roles and responsibilities of the interprofessional health care team. Thus, the results of this pilot student point to the potential use of simulation as a means to assist students to gain insight and an understanding of the roles and responsibilities of the various members of the interprofessional health care team. The knowledge gained can then be utilized by students to assist them to make a more informed and confident career choice when declaring their college majors and discipline of study.

\section{Future Study Recommendations}

Longitudinal studies need to be conducted to assess if students who participate in programs such as this have a reduced rate of attrition and programmatic changes during the pursuit of their baccalaureate degree as opposed to students who do not participate in a simulated recruitment programs.

\section{References}

Ateah, C.A., Snow, W., Wener, P., MacDonald, L., Metge, C., Davis, P., Fricke, M., Ludwig, S., \&Anderson, J. (2010). Stereotyping as a barrier to collaboration: Does interprofessional educationmake a difference? Nurse Education Today, 31, 208-213.

Barnes, D., Carpenter, J., \& Dickinson, C. (2000). Interprofessional education for community mentalhealth: Attitudes to community care and professional stereotypes. Social Work Education, 19, 565-583.

Hean, S., Clark Macleod, J., Adams, K. \&Humphris, D. (2006). Journal of Interprofessional Care, 20(2), 162-181

McDowell, J., Styles, K, Sewell, K., Trinder, P. Marriott, J., Maher, S. \& Naidu, S. (2016). InstructionalDesign and Assessment. A Simulated learning Environment for Teaching Medicine Dispensing Skills. American Journal of Pharmaceutical Education, 80(1), 1-11).

Lave, J. \& Wenger, E. (1991). Situated Learning. Legitimate peripheral participation.

New York: Cambridge University Press.

Oxelmark, L., Amoroe, T.N., Carlzon, L. \&Rystedt, C. (8, April 2017). Students' understanding of teamwork and professional roles after interprofessional simulation - a qualitative analysis. Advances In Simulation, 2,8. Retrieved from: https://advancesinsimulation.biomedcentral.com/articles/10.1186/s41077-017-0041-6

Rogers, M. Inside Higher Ed. (2013, November 27). STEM-ming the Tide. Retrieved from:

https://www.insidehighered.com/news/2013/11/27/study-tracks-attrition-rates-stem-majors

United States Census Bureau. (2017, April, 10). An aging nation. Retrieved from:https://www.census.gov /library/visualizations/2017/comm/cb17-ff08_older_americans.html

United States Department of Labor: Bureau of Labor Statistics. (2017, October, 24). Healthcare Occupations. Retrieved from: https://www.bls.gov/ooh/healthcare/home.htm

U.S. Department of Education. (2013). STEM Attrition: College Students' Paths Into and Out of STEM Fields Statistical Analysis Report. (NCES 2014-001). Washington, DC: NCES, IES, U.S. Department of Education.

Vardi, I. (2015). Manual of Simulation in Health Care (2 ${ }^{\text {nd }}$ ed.). New York, NY: Oxford University Press. http://stel.bmj.com/pages/authors/\#submission_guidelines 